\title{
LINHAS DE PESQUISA DA PÓS-GRADUAÇÃO EM GEOGRAFIA. MUDANÇAS, ESQUECIMENTOS E EMERGÊNCIA DE (NOVOS) TEMAS
}

\section{research lines of postgraduate studies in geography. changes, oblivions and emergence of (new) topics}

\author{
Sandra Lencioni ${ }^{1}$
}

$a_{a} \boldsymbol{a}_{a a}$

\begin{abstract}
Resumo
A institucionalização da pesquisa em nível de pós graduação no Brasil vem se expandindo por todo o território brasileiro. A supervisão deles é de responsabilidade de cada universidade e da CAPES, instituições que estão sob uma conjuntura neoliberal. Nesse artigo se discute o uso e abuso da palavras missão, muito empregada por esses organismos, bem como a perspectiva mercantil que os influenciam, com o objetivo de exemplificar a influência desse contexto neoliberal. Em seguida, a análise das linhas de pesquisa em Geografia busca compreender porque alguns temas emergem com força enquanto outros são esquecidos.
\end{abstract}

Palavras-chave: Programa de pós-graduação, Linhas de pesquisa, Geografia.

\begin{abstract}
The research institutionalization of research at postgraduate level in Brazil has been expanding throughout the Brazilian territory. Their supervision is the responsibility of each university and CAPES (funding agency of the Ministry of Education), institutions under a neoliberal context. In this article we discuss the overuse of the word mission, often employed by these organizations, as well as the commercial perspective that influence them, in order to illustrate the influence of neoliberal context. Then, the analysis of the postgraduate lines of research in Geography seeks to understand why some themes emerge strongly while others are forgot.
\end{abstract}

Key words: Postgraduate, Lines of research, Geography.

\section{Résumé}

L'institutionnalisation de la recherche de maîtrise et doctorat au Brésil est en expansion par le territoire brésilienne. La surveillance de ces est de la responsabilité de chaque université et de la CAPES (institution brésilienne pour la promotion de l'enseignement supérieur), organismes que sont sous une conjoncture néolibéral. Dans cet article, nous discutons l' usage et l' abus de le mots mission, beaucoup employé par ces organisations et encore la perspective mercantiliste que les influencent afin d'illustrer l'influence du contexte néolibéral. Ensuite l' analyse de les lignes de recherche en Géographie cherche à comprendre pourquoi certains thèmes émergents tandis que d'autres sont oubliés.

Mots clés: Master et doctorat, Ligne de recherche, Géographie.

(1) Bolsista Produtividade do CNPq e Prof ${ }^{a}$. Dr ${ }^{\mathrm{a}}$. do Programa de Pós-Graduação em Geografia Humana da Universidade de São Paulo - Rua Lineu Prestes, 338. CEP: 01060-970. São Paulo (SP), Brasil. Tel: (+55 11) 30322217 - slencion@usp.br

\section{aa $\mathbf{a} a$}




\section{INTRODUÇÃO}

Não há dúvida alguma que a institucionalização da pesquisa no nível de pós-graduação no Brasil e, em particular no campo da Geografia, vem passando por mudanças profundas. Hoje, os programas de pós-graduação, particularmente os de Geografia, atingem um número expressivo e estão mais bem distribuídos no território brasileiro. Diplomas e títulos de mestre e doutor são auferidos em instituições de ensino e pesquisa do Nordeste, Centro-Oeste, Sul e Sudeste. A região Norte não tem, ainda, em 2013, doutorado e essa situação precisa ser urgentemente equacionada, por tudo que a Amazônia representa para o país.

Esses títulos obtidos, quer em universidade em que a pós-graduação está estruturada há anos, contando com ampla experiência na formação de mestres e doutores, quer em universidade em que a pós-graduação é recente, são títulos análogos e comparáveis entre si. Essa equivalência só foi possível de ser alcançada porque a institucionalização e o crescimento do número de programas de pós-graduação e sua melhor distribuição geográfica em âmbito nacional se fizeram acompanhar de políticas específicas, como as implementadas pela CAPES - Coordenadoria de Aperfeiçoamento de Pessoal do Ensino Superior - , fundação do Ministério da Educação. Sem essas políticas nacionais não seria possível ter a mesma equivalência os títulos obtidos em instituições de ensino com trajetórias tão distintas. Por exemplo, se não fosse essa equivalência um título obtido no programa de pós-graduação mais antigo do Brasil, o da Universidade de São Paulo cuja primeira tese em Geografia foi defendida em 1946, não poderia ser equiparável com um obtido num programa de pós-graduação recém criado.

Essa observação é digna de nota porque paira um certo reducionismo no meio acadêmico que apreende a atuação da CAPES relacionada apenas ao apoio financeiro dado aos programas de pós-graduação e, principalmente, à avaliação dos programas de pós-graduação. Esses dois aspectos — apoio e avaliação — estão diretamente relacionados entre si, pois atualmente dependendo da nota atribuída ao programa é que é disponibilizado aporte financeiro; quanto maior a nota, maior o será o recurso disponibilizado.

Os critérios definidores da avaliação são estabelecidos pela comunidade científica, por meio de um sistema de representação em comissões hierarquicamente organizadas. Acima dos Comitê de áreas há o CTC — Conselho Técnico Científico — que tem entre seus integrantes os representantes das grandes áreas do conhecimento. Ele avalia a pertinência do que é proposto por cada área. É absolutamente verdade que a CAPES não define direta e autonomamente os critérios de avaliação, mas é igualmente verdade que esses critérios ao serem institucionalmente construídos e definidos pelas diferentes áreas do conhecimento e inseridos em representações hierarquicamente dispostas, terminam favorecendo aquelas áreas com maiores afinidades e força política, que no CTC acabam determinando o que é mais desejado e esperado de um programa de pós-graduação.

Dessa maneira os programas tendem a se curvar, ora mais, ora menos, aos parâmetros determinados, pois a disponibilidade dos fundos financeiros pela CAPES se tornou fundamental para o funcionamento deles. Como corolário dessa situação, os programas de pós-graduação tenderam as ser atingidos em sua autonomia e, consequentemente o foi, também, a própria Universidade. Não seria nenhum exagero afirmar que a própria ideia de autonomia universitária se vê abalada com esta situação. Aqui, nessa questão sobre a autonomia da Universidade é que se coloca a face contraproducente da dependência dos programas de pós-graduação a um organismo centralizador externo. Cada programa sente as restrições, titubeia nas ousadias muitas vezes necessárias ao desenvolvimento da ciência, porque essas podem se traduzir em irresponsabilidade institucional, uma vez que pode comprometer os fundos que sustentam o programa. Cada Universidade experimenta, assim, amarras. Localizá-las é fundamental para saber lidar com elas e buscar superar essas amarras é fundamental, o que implica numa ação política que deve ser exercida por meio da ação política nos vários órgãos, instituições, sociedades e associações reconhecidas como entes legítimos de diálogo com a CAPES. 
Essa é a faceta que a primeira vista poderíamos chamar de deletéria, mas um olhar mais atencioso vislumbrará que graças a essa forma centralizada da avaliação é que plausível equiparar as titulações; que é possível fazer valer o título de mestre ou de doutor dado por um programa aos outros títulos atribuídos por outros programas. Foi por meio desse sistema único de avaliação que foi possível se chegar a equivalência dos títulos no Brasil.

Claro que como toda avaliação, a avaliação dos programas tem um sentido de apreciação e de julgamento; no caso, que emana de fora dos programas e das Universidades. E isso causa um certo desconforto. Contudo, quando examinamos o sentido da avaliação e percebemos que é ela que permite a equivalência dos títulos, torna-se nítido que a face negativa da avaliação se dilui na positiva.

Se os programas recebessem fundos das próprias universidades e se se concebesse uma outra forma de equiparação dos programas, estaríamos, por certo, discutindo outros limites, como, por exemplo, aqueles dados pelo fundos disponíveis para os programas de pós-graduação que, por certo variariam segundo o orçamento de cada universidade, ou aqueles oriundos da discrepância de qualidade e da exigência variada e múltipla dos vários programas.

Todo sistema de avaliação apresenta limites. Isso é uma verdade. Nenhum aspecto da pós-graduação deve ser resguardado de discussão e todo sistema deve passar constantemente por uma análise crítica. Pode, inclusive, haver retrocessos nas mudanças, mas o que vale, é importante dizer, é a tentativa de corrigir a situação e projetar perspectivas que contribuam para o aprimoramento do sistema de pós-graduação, em particular, da forma com que se está produzindo conhecimento.

Enquanto a avaliação tem sua face constrangedora e indutora de projetos e prática, as linhas de pesquisa de cada programa gozam de inteira liberdade, pois os programas podem livremente definir suas linhas de pesquisa. Em outros termos, a definição das linhas de pesquisa pelos programas se constitui num espaço de liberdades. Aí, valorizam-se temas, enquanto que outros encontram ostracismo. Isso não se dá ao acaso, tem sentido e é coletivamente produzido. No entanto, muitas vezes presencia-se a inconsciência dos por quês.

Sobre esse espaço de liberdades, num quadro de constrangimentos é que as ponderações a seguir se inserem. Primeiro, situando a pesquisa e a universidade no cenário atual, destacando alguns traços que revelam a incidência da influência neoliberal. Sem essa compreensão é limitado o entendimento das mudanças, do esquecimento e da emergência de (novos) temas. Essa influência, é fundamental dizer, é mais pressentida do que conscientemente consentida. Segundo, comentando algumas características das linhas de pesquisa desenvolvidas nos programas, buscamos compreender as mudanças, os modismos e seus sentidos.

A análise se situa no ano de 2012, o último ano em que, em 2013, os dados e as informações sobre cada programa foram divulgados pela Capes. O total do número de programas examinados é de 48. Historicamente, o número de programas tem aumentado, em especial no interior do país.. Acresce-se a esse número 1 mestrado profissional que não faz parte da análise. Diz respeito ao da UNESP (Universidade Estadual Paulista Júlio de Mesquita Filho), campus de Presidente Prudente.

\section{O CONTEXTO DAS MUDANÇAS DOS PROGRAMAS DE PÓS-GRADUAÇÃO NO BRASIL. A PERSPECTIVA NEOLIBERAL E O ENSINO SUPERIOR VISTO PROGRESSIVAMENTE COMO NEGÓCIO}

A perspectiva neoliberal, em especial a sua influencia nos anos 90 do século XX, contaminou a universidade fazendo com que a ideia de universidade e do conhecimento como um bem público fosse desalojada pelos aspectos econômicos da educação e da universidade como negócio. Essa visão do ensino superior como um negócio, não é novidade recente, mas a partir desses anos essa perspectiva passou a orientar, como nunca, os projetos de educação superior. Tal perspectiva mercantil alcançou seu apogeu quando a OMC — Organização Mundial do Comércio — ao firmar o GATS - Acordo Geral para o Comércio e Serviços - procurou colocar a educação superior como uma mercadoria a ser regulada por esse acordo e a ser objeto de negociação nesse tipo de organismo. 


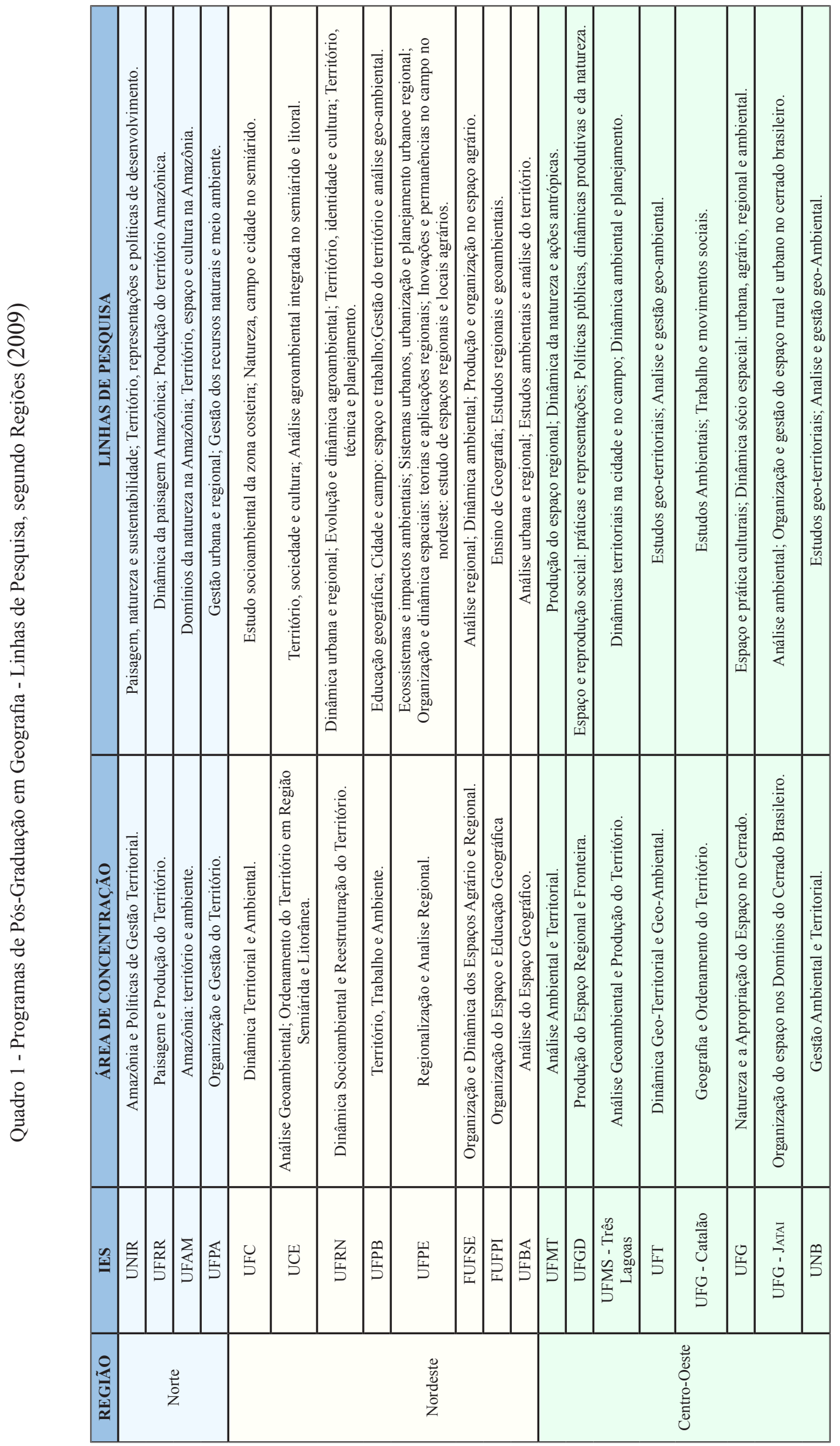




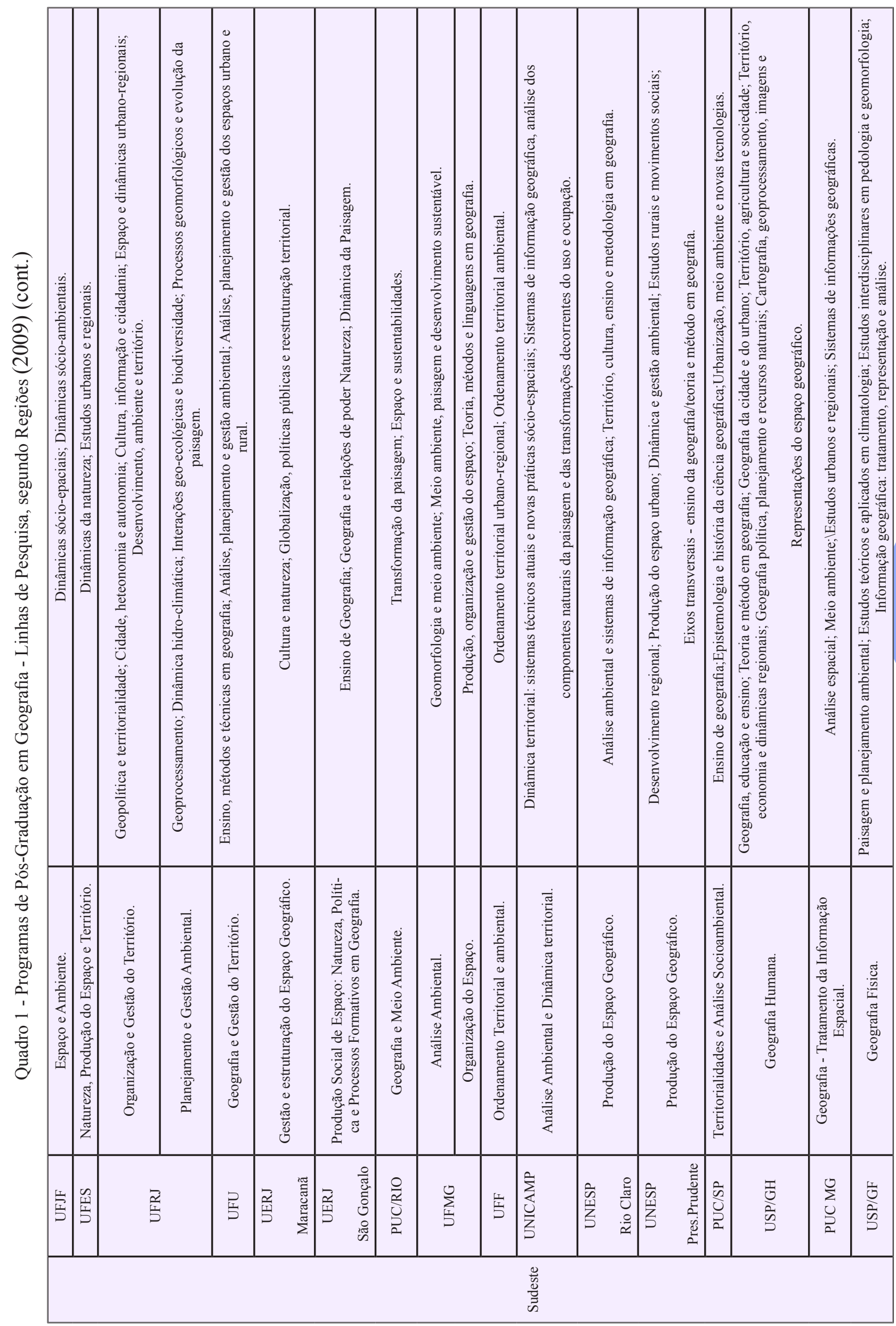




\begin{tabular}{|c|c|c|c|c|c|c|c|c|c|c|c|}
\hline 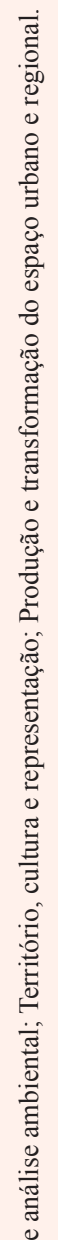 & 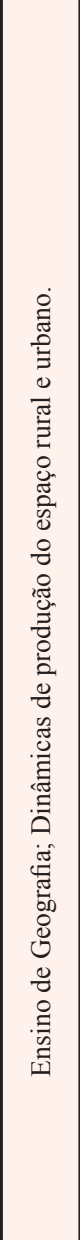 & 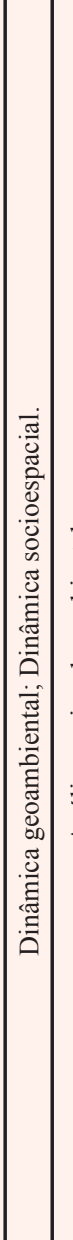 & 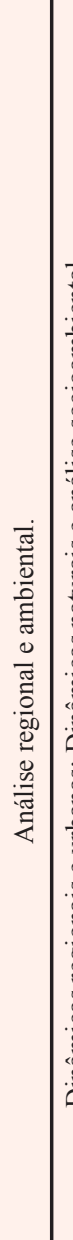 & 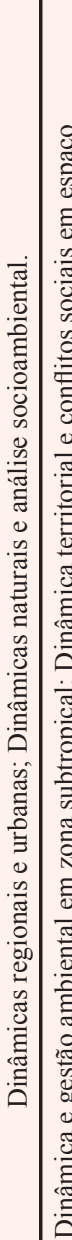 & 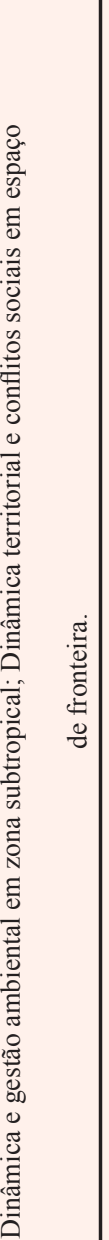 & 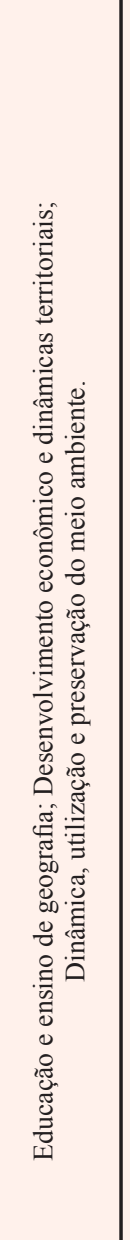 & 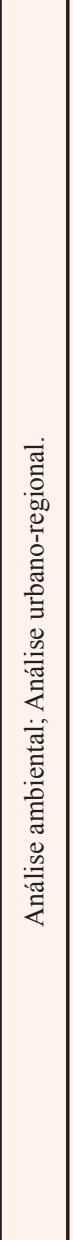 & 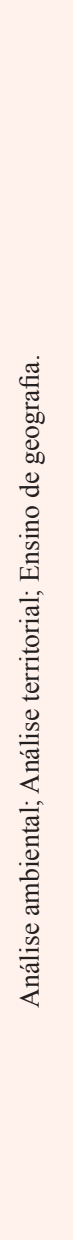 & 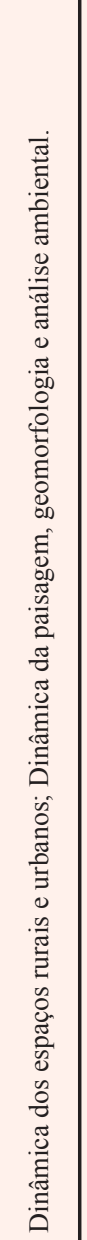 & 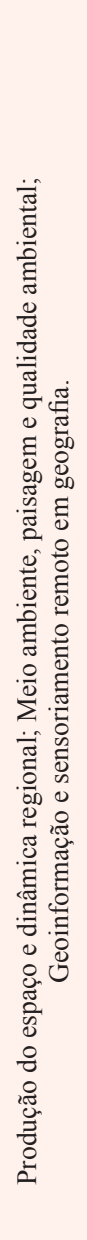 & 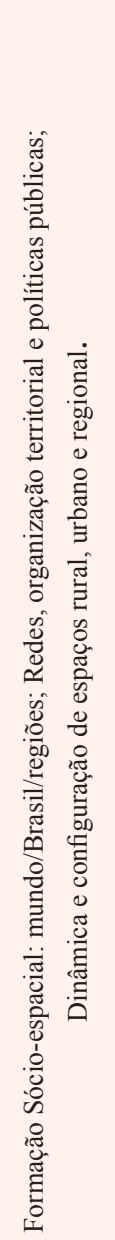 \\
\hline 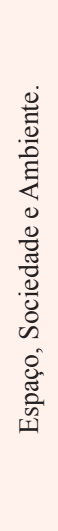 & 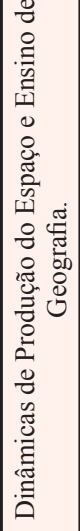 & 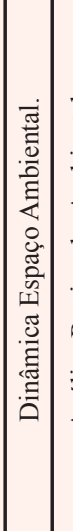 & 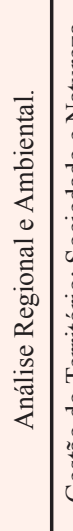 & 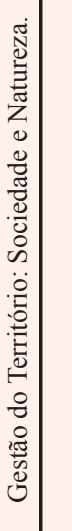 & 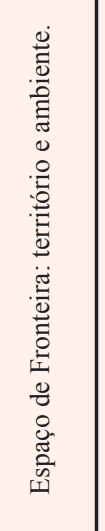 & 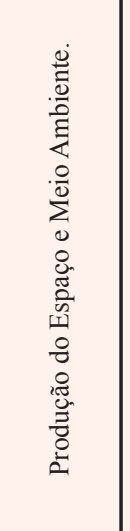 & 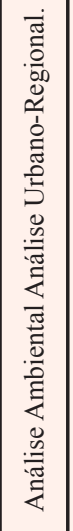 & 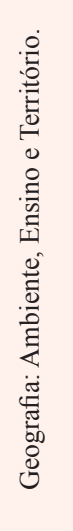 & 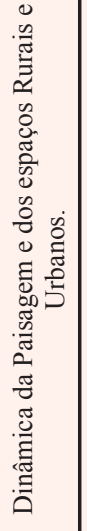 & 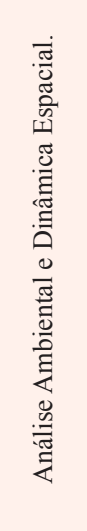 & 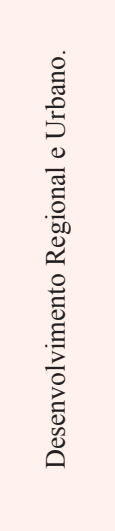 \\
\hline $\begin{array}{l}\text { 总 } \\
\text { 空 }\end{array}$ & 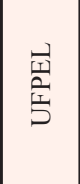 & 島 & $\sum_{-1}^{\Sigma}$ & 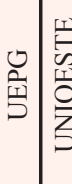 & 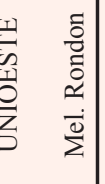 & 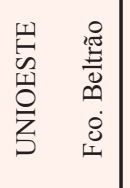 & $\begin{array}{l}0 \\
\text { s. } \\
\text { s. }\end{array}$ & 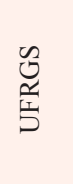 & 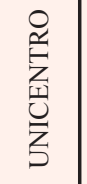 & $\begin{array}{l}\sum_{\infty} \\
\text { 荡 }\end{array}$ & $\begin{array}{l}\text { D } \\
\text { I }\end{array}$ \\
\hline \multicolumn{12}{|c|}{$\overline{\bar{n}}$} \\
\hline
\end{tabular}

Revista da ANPEGE, v. 9, n. 11, p. 5-19, jan./jul. 2013. 
Ao mesmo tempo, os investimentos estrangeiros nas universidades do Brasil e da América Latina cresceram exponencialmente. Alguns exemplos ilustram o que queremos dizer. A Universidade de Bologna tem uma sede em Buenos Aires e a Laureate Education, dos Estados Unidos, detém atualmente, em 2013, 51\% da Universidade Anhembi Morumbi. A Rede Laureate se constitui num dos maiores grupos internacionais de universidades do mundo, tendo mais de 75 instituições que atua em pouco mais de 30 países. Vale lembrar, também, a universidade americana DeVry, que atua em mais de 400 países e que se associou com a Fanor — Faculdades Nordeste —, a Faculdade Ruy Barbosa, a Faculdade Boa Viagem (FBV), a Faculdade do Vale do Ipojuca (FAVIP) e a Faculdade Diferencial Integral (Facid). Possui cerca de 110.000 estudantes em todo mundo, sendo 27.000 brasileiros.

Esses são apenas alguns exemplos dos negócios que envolvem a graduação e a pós-graduação, em especial a lacto sensu, revelando aspectos novos do ensino superior como atividade econômica empresarial. O peso dessas empresas privadas é grande, pois abrangem $78 \%$ dos alunos do ensino superior. Deve-se observar que muito dos recursos financeiros dessas universidades provém de fundos de investimentos e deriva daí o fato desses fundos deterem quase a totalidade das maiores empresas privadas da educação superior no Brasil.

A ideologia neoliberal permeia a ideologia da maioria das instituições privadas. Ficando só nesses dois exemplos dados, podemos ver sua influência de forma bastante direta e clara. A Universidade Anhembi-Morumbi diz que sua "missão é prover educação de alta qualidade, formando líderes e profissionais capazes de responder às demandas do mundo globalizado e contribuir para o progresso social com espírito empreendedor e valores éticos ". A Fanor divulga seus valores teach, dentre os quais se destaca, por exemplo, o trabalho em equipe e comunicação, em que uma das assertivas é: eu contribuo para o sucesso do meu time. E, os seguintes valores: honestidade + responsabilidade $=$ sentimento de propriedade, no qual uma das afirmações em destaque é a seguinte: "eu tomo decisões como dono da empresa".

Os termos: missão da universidade, atendimento às demandas da globalização, desenvolvimento do espírito empreendedor, sucesso do meu time e sentido de propriedade privada alcançam a universidade vista, até então, como lugar de crítica, de construção ética da ideia coletiva e como espaço de liberdade.

O ensino superior privado se volta, principalmente, para os cursos de graduação, enquanto que ao falarmos em programas de pós-graduação o peso maior se situa nas universidades públicas. No caso da geografia, a totalidade deles está inserida em universidades públicas ou confessionais. Mas longe do que se pode imaginar não estão resguardados das influências de uma visão mercantil e neoliberal. Muito pelo contrario, estão vulneráveis a essa perspectiva até porque nem sempre têm consciência clara do contexto no qual se inserem.

Em outros termos, temos de um lado a expansão do ensino superior privado no Brasil, em especial relativo aos cursos de graduação e orientados como uma atividade empresarial submetida às leis do mercado. De outro, as universidades públicas e as confessionais, como a PUC — Pontifícia Universidade Católica - como centro da pós-graduação no Brasil. Esses dois lados são dois lados opostos? Dois lados estranhos um ao outro?

Parece que sim. Mas esse sim absoluto trata-se tão só de uma aparência. Seria enganoso considerar que isso tudo está distante da discussão das linhas de pesquisa da pós-graduação em Geografia no Brasil. Pelo contrário, está muito próximo porque é esse contexto neoliberal, que entende a universidade como negócio, que se contextualiza a pós-graduação hoje em dia e se concebe as linhas de pesquisa em Geografia.

Cremos que o melhor exemplo advém da mudança do emprego da ideia de fins da universidade para o emprego da de missão da universidade. Antigamente, se falava nos fins da universidade, hoje em dia se fala em sua missão. Podemos atribuir essa mudança à influência da língua inglesa ou como espelhamento nas universidades americanas. Isso é um fato, mas a explicação não passa 
de meia verdade, pois seu significado é mais profundo. Entre os vários sentidos da ideia de fim, aparecem os de objetivo e de propósito, ao passo que a palavra missão relaciona-se a duas conotações particulares e específicas.

Uma é de natureza religiosa e, a outra, a de que alguém deve ter a incumbência de executar um pedido ou uma ordem. O primeiro sentido traz para o interior das universidades públicas, cuja natureza é laica e secular, o sentido clerical.

O segundo sentido tem a ideia de delegar tarefas. Ou seja, numa missão, alguém deve ter a incumbência de executar um pedido ou uma ordem de outro. Nós da universidade devemos executar um projeto que vem de fora, emanado de fora? Devemos executar um projeto emanado pela "mão invisível do mercado" ? Ora, o uso do termo missão compromete a ideia de que cabe à Universidade elaborar seus próprios fins e não de delegar a outro essa incumbência. $O$ uso da palavra missão externaliza o projeto da Universidade, pois cabe a ela executar um projeto que se situa fora dela, que é concebido por outrem que lhe confere uma missão.

Perguntamos, se concebido por outro, quem seria esse outro? Onde ele se situa? No mercado? Os folders de divulgação dos programas de pós-graduação devem se espelhar nos folhetos das empresas e nos sites em que a palavra missão é largamente empregada? Não é do interior do próprio programa de pós-graduação que deve emanar seus fins? Ele cumpre uma missão determinada por outro, ou define a si próprio mostrando suas características?

Por certo, o uso do vocábulo missão é inconsciente, tanto quanto o sumiço das palavras finalidade e objetivo até então referidas aos programas. Mas, mesmo que admitamos inconsciência na substituição das palavras finalidade e objetivo pela palavra missão, seu emprego indiscriminado revela, infelizmente, anestesia de nossa consciência crítica. O mercado, como oráculo tutelar, com sua "mão invisível" acaricia a universidade e não percebemos que nos espelhamos em propagandas de empresas privadas. Ainda bem que os programas de pós-graduação em geografia das várias PUC continuam falando em taxa de matrícula e em mensalidades, não tendo aderido a moda de usar o nome de investimento. Sim, taxa de matrícula e mensalidades aparecem, agora, como investimento. Os termos se alteraram. De fato, a educação é cada vez mais vista como um negócio.

A ideia de mercado está tão presente que a referência a apoios recebidos, por exemplo, para a publicação de um livro ou para participação em congressos, tem sido mencionada como patrocínio. Antes, a comunidade acadêmica usava o termo apoio. Substituiu-se essa palavra pela palavra patrocínio que é própria da linguagem empresarial e, assim, não se vai dando conta do mergulho numa perspectiva que mercantiliza e instrumentaliza o conhecimento e a pós-graduação.

Essa perspectiva mercantil se faz notar em muitos outros aspectos, mas vamos apresentar mais um apenas, que diz respeito à ideia de concorrência. A concorrência é imanente à ideia de mercado e, nesse sentido, a perspectiva neoliberal da universidade acentuou a ideia de ranqueamento, de classificação. A ideia de melhor e de primeiro acompanha a influência da universidade americana no Brasil, inserindo tudo numa perspectiva muito mais competitiva, do que cooperativa. Mesmo as ações de cooperação não deixam de ter o traço da competição, pois os programas que desenvolvem cooperação se colocam em melhores condições de competição perante aqueles que não estabelecem parcerias. Como decorrência, instala-se a competição em várias atividades e cada programa busca alçar a um lugar, se não no topo da lista, pelo ao menos a um lugar que considera adequado e razoavelmente confortável.

Esses ranqueamentos, em si, não são deletérios; contudo, passam a ser quando a competitividade se constitui na motivação da produção do conhecimento atingindo o ponto de, inclusive, o esterilizar, a despeito dos indicadores positivos e em elevação. A produção do conhecimento parece crescer, mas no fundo, o que há é, em geral, um empobrecimento das ideias, repetições, pouca inovação e saber. Além desse aspecto, essas classificações podem conter germes de perversidade e, mais acertadamente, de desprestígio. Por exemplo, ao se reconhecer que um dado programa é de excelência, de roldão se está desprestigiando aqueles que não conseguiram, ainda, esse rótulo. 
Esses exemplos mostram como a inconsciência que paira sobre a situação dos programas de pós-graduação torna mais difícil a superação dos problemas, até porque esses estão obscurecidos. Sem localizar o calcanhar de Aquiles não podemos acertar a mira para a inflexão, por isso é fundamental termos consciência do que vem ocorrendo, aguçarmos a crítica o tempo todo, pois se constitui numa verdadeira heresia a inconsciência institucionalizada sobre o contexto da produção do conhecimento servir de base para a formação de pesquisadores de forma alienada na universidade.

\section{AS LINHAS DE PESQUISA EM GEOGRAFIA: CARACTERÍSTICAS, MUDANÇAS, MODISMOS E SENTIDOS}

Importa notar desde logo que aqui não se objetiva fazer uma análise exaustiva dos programas de pós-graduação em geografia no Brasil, mas apenas o de realizar uma apreciação geral das mudanças recentes nas temáticas que esses programas vem desenvolvendo. Inicialmente, havíamos pensado em nos debruçar detalhadamente sobre as linhas de pesquisa, mas o primeiro exame sobre elas revelou fragilidades que comprometem qualquer consideração mais estrita e particularizada. Muito disso se deve à não correspondência entre as linhas de pesquisa anunciadas e as pesquisas realizadas pelos programas. Por exemplo, podemos encontrar linhas registradas sem que tenha havido alguma pesquisa sobre o assunto, bem como podemos ver temas desenvolvidos pelo programa sem que haja uma linha de pesquisa que lhes sejam correspondente. Há, repetindo, uma inadequação entre a linha registrada e a pesquisa de fato realizada.

Inconsistências desse tipo, tanto quanto outras revelam debilidades na particularização, pois levariam a veredas sinuosas, falsamente esclarecedoras e a conclusões equivocadas. Por isso, a opção foi de tomar como referência apenas as linhas de pesquisa mais gerais, arroladas no caderno Proposta do Programa (Caderno de Indicadores) presentes no portal da CAPES. Essas linhas e a correspondência com as áreas de concentração e a universidade a qual se inserem estão listadas no final do texto.

Do exame realizado nas linhas de pesquisa dos programas de pós-graduação, selecionamos alguns aspectos para nos referirmos, como exemplo do que pretendemos, que é o de nos aproximarmos da compreensão do porque das mudanças.

Iniciamos com a observação seguinte: nos programas tende a predominar a palavra ambiente e não a palavras natureza e recursos naturais. Esse fato indica uma mudança importante, pois anteriormente era o inverso. Como decorrência se faz presente as expressões correlatas, como análise ambiental e meio ambiente, bem como o uso da palavra ecológico.

A compreensão dessa mudança abarca vários sentidos. Um deles pode parecer mais significativo, mas nos parece mais enganador. Poderíamos atribuir a emergência dessa noção ao fato da palavra ambiente ser sobejamente referida, estando na ordem do dia invadindo a mídia e, portanto, sendo resultado de um modismo. Não se trata disso, de modismo, embora apareça como se fosse por seu efeito espetacular. Não é modismo porque um modismo que se generaliza deixa de ser modismo, pois comprometeu seu sentido de novidade e de particularidade. E, também, não é modismo porque essa mudança não é efêmera. Tudo parece indicar que o desprestígio da palavra natureza deve-se ao fato dessa palavra carregar, em si, o peso da lembrança da divisão do conhecimento entre ciências naturais e ciências da sociedade.

Como herdeiros de La Blache essa lembrança é angustiante, mesmo que na prática, no percurso de pesquisador, se coloque a tradição de que haveria a necessidade de escolher entre duas opções básicas: pela geografia física ou pela geografia humana. Opção feita, angústia escondida, problemas obscurecidos. Na verdade, a angustia de conhecer é camuflada; pois o caminho seguro para o conhecimento deixa de sê-lo e nos amedronta quando ao enveredar nele nos colocamos questões de âmbito epistemológico. Somos o que somos, herdeiros de uma tradição na qual a delimitação dos campos do saber caracterizam a ciência moderna e, como consequência, a própria segmentação interna da geografia, em física e humana. A evolução crescente das especializações fragmentaram, 
ainda mais intensamente, a ciência. Terminamos o século XX diante de frações do conhecimento cada vez menores, cada vez mais verticalizados. A própria segmentação interna da Geografia também seguiu o mesmo caminho da especialização.

Isso não quer dizer que a relação entre os campos do saber fosse desconhecida. Isso não é verdade, pois simples termos usados na geografia atestam as influências entre as várias áreas do conhecimento. Algumas expressões usadas na geografia certificam essa afirmação. Da anatomia usamos, por exemplo, as expressões: 'artérias urbanas', 'coração da planície' e 'braço de um rio'. Da botânica, exemplificando, utilizamos 'formas arborescentes e dendríticas'; da química, 'difusão por osmose dos fluxos'; da física, 'forças de atração e repulsão', 'campo gravitacional'...

Terminamos o século XX com a percepção de que o estilhaçamento cada vez maior dos fragmentos do saber mostrou limites ao conhecimento e necessidade de desenvolver relações entre os campos disciplinares e entre a multiplicidade de especializações. Em resumo, o que está posto é a necessidade de unificação da fragmentação historicamente construída, que no âmbito de todas as ciências, quer no seio da própria geografia. O desafio é o de alçar a um patamar novo de compreensão e explicação do real que supere a fragmentação excessiva do saber. Por isso é que, hoje em dia, as interfaces dos ramos particulares do conhecimento vem se tornando, progressivamente, valorizadas. Novos campos do conhecimento despontam na busca de união, a exemplo da engenharia genética (engenharia + genética) e da biotecnologia (biologia + tecnologia)...

As disciplinas, se já não travam um diálogo cada vez maior entre si, apresentam necessidade de maior interpenetração. É como se a história nos tivesse dizendo: construam pontes entre os saberes porque sem elas não poderemos atravessar o século XXI e continuaremos falando e pensando como no século passado. Por isso, não por modismo, é que a palavra ambiente emerge no lugar do vocábulo natureza, cuja história lembra o divórcio realizado com intensidade, durante o século $\mathrm{XX}$, entre a forma de se conhecer a natureza e a sociedade.

E é isso que explica também que são os pesquisadores voltados para as questões do ambiente que mais superaram a clivagem entre esferas do conhecimento relativas à geografia física e à geografia humana, muito embora o trato da espacialização dos processos sociais ainda se faça de modo tímido e, muitas vezes, superficial e reduzido à questão da ação antrópica. É mais frequente o estabelecimento de relações entre os campos do saber próprios da geografia física e das ciências da natureza e menos comum o estabelecimento de relações com os campos do saber próprios da geografia humana. Mas, não resta dúvida que mesmo que reduzido à questão da ação antrópica há um esforço de superação das antigas rupturas herdadas de um conhecimento fragmentado. No caso quase de um do caminho inverso, do trato dos aspectos naturais por aqueles que enfatizam os processos sociais, o trato com a dimensão da natureza muitas vezes a vê como um palco da ação humana, uma condição destituída de interações, movimentos e processos. A nosso ver, bem mais tímido e insuficiente do que as análises elaboradas por aqueles que colocam em relevo a dinâmica da natureza, de tradição em pesquisa na área da geografia física.

O século XXI anuncia o momento de superar os particularismos extremados, de estabelecer a relação entre os fragmentos do saber para se chegar a um grau mais universal e avançado de explicação e compreensão do real. Mais por essa necessidade de integração do conhecimento, e não por modismos, é que se impõe a palavra ambiente e vocábulos correlatos. Nos programas é frequente os vocábulos: zoneamento ecológico-econômico, diagnóstico socioambiental, biodiversidade, análise ambiental... Todos esses termos e seus derivados estão bastante presente nas propostas dos programas de pós-graduação em geografia. Como dissemos, a palavra natureza e o termo recursos naturais aparecem em menor número e com muito menor ênfase que a palavra ambiente. Essa palavra e esse termo lembram os tempos de ruptura entre a geografia física e a geografia humana, enquanto que esses outros termos anunciam a possibilidade da produção de um conhecimento mais integrado, em grande parte afeito, ainda, ao âmbito das particularidades herdadas no campo da própria geografia física. 
Nesse cruzamento, em que o velho não mais satisfaz e o novo é pouco consolidado, é compreensível que haja dificuldades na formulação das linhas de pesquisa e, muito mais ainda, no currículo de geografia, pois ambos traduzem, cada um a seu modo - ainda mais o currículo de graduação - a construção de uma identidade coletiva do programa ou, no segundo caso, do curso de graduação. Tanto as linhas de pesquisa como os currículos não se desvinculam de um projeto coletivo de desenvolvimento da ciência geográfica. Esse fato é que permite entender o calor e os embates nas discussões sobre currículo, pois no fundo o que está posto é a questão da construção da identidade coletiva no fazer da geografia. Muito embora na ciência deva prevalecer a razão, o âmbito acadêmico, não nos esquecemos, se constitui numa arena, também política e de luta, nem só por ideias, mas por ideais.

A segunda observação diz respeito à importância crescente da técnica no desenvolvimento das pesquisas. Poder se-ía afirmar que as coisas não se colocam dessa maneira, que há um certo exagero nessa afirmação. Claro, podemos estar equivocados, pois podemos nos iludir facilmente pela aparência das coisas, que permite levar a muitos enganos, como o de acreditar que o sol girava em torno da Terra, como entendeu Ptolomeu. Mas, não é o caso. Não se trata de nenhuma ilusão considerar que o mundo está invadido pelas técnicas, uma vez que nossa experiência cotidiana é permeada intensamente pela técnica

É um mundo real, material e imaterial. Mas é, também, virtual, no sentido de ter a capacidade de emular, de comportar-se como sendo o outro. Por exemplo, por meio da informática, se cria a possibilidade de imitar operações mentais dos homens. Não se trata porém, de simples aparência se constatar o quanto o mundo contemporâneo está invadido pelas técnicas e o quanto ele é virtual, pois a experiência da vida nos dias atuais, repetindo, é permeada e potenciada no tempo e no espaço pela virtualidade e, em especial, pelas tecnologias da informação e das comunicação.

Esse mundo, redimensionado pelo progresso técnico levou ao desenvolvimento de teorias em geografia que buscaram acentuar a dimensão técnica da contemporaneidade, a exemplo de alguns trabalhos de Milton Santos e do exemplo da retomada da nova roupagem e do avanço teórico e metodológico da discussão das redes, que se transfiguraram face à revolução da informação e comunicação. Também, significou o desenvolvimento de campos específicos do conhecimento como os Sistemas de Informações Geográficas, SIG.

Esse contexto fez com que a questão técnica passasse a figurar com força entre os temas da geografia, aparecendo com nitidez nas Propostas dos Programas e bastante transparente em muitos títulos de dissertações e teses, bem como na produção intelectual dos docentes. Há vinte anos atrás termos como técnicas, tecnologia e sistema técnicos eram praticamente ausentes nos títulos dos trabalhos acadêmicos, enquanto que hoje são bastante correntes e já não se reduzem a solução de tratamento de dados e problemas de quantificação.

Por outro lado, essa nova realidade coloca à disposição do pesquisador uma grande quantidade de dados e informações que podem ser correlacionadas e sintetizadas de maneira mais rápida e eficiente por meio de recursos técnicos, de softwares e de novos instrumentos de análise. Natural, portanto, que diversas formas de modelagem figurem como preocupação acadêmica num quadro em que se desenvolvem linhas de pesquisa voltadas ao geoprocessamento, entendido como um conjunto de geotecnologias que se complementam.

A hora é a do geoprocessamento, da geocartografia, dos sistemas de informações geográficas, das representações gráficas, etc. Esse é o novo. Na apresentação das linhas de pesquisa — as mais gerais, lembrando mais uma vez - o grande sumiço foi da palavra cartografia, que só figura uma única vez, no programa de pós-graduação em geografia humana, da USP.

Como terceira observação gostaria de tecer algumas considerações em relação à presença acentuada do termo gestão e ao desprestígio do vocábulo planejamento. A palavra gestão aparece nos títulos das linhas de pesquisa, duas vezes mais (um pouco mais até) que a palavra planejamento. Falar em planejamento, desenvolver pesquisas discutindo o planejamento já teve seus dias de 
gloria. Isso porque falar em planejamento apareceu como algo novo, quase como uma palavra de ordem no sentido de se fazer geografia relacionada à ação do Estado. Ação de um Estado planejador, emanando dele e de suas competências internas os planos de desenvolvimento em diversas escalas, em diversos assuntos e em diferentes temas. Planos nacionais de desenvolvimento, planejamento regional, planos de integração da Amazônia, etc..

Hoje em dia se fala mais em gestão, em governança e em ordenamento territorial e menos em planejamento. Se atentarmos para o sentido da palavra planejamento veremos que ela diz respeito ao ato de planejar. Já a palavra gestão se refere ao ato de gerir. Em suma, enquanto planejar significa elaborar um plano, um projeto; gerir quer dizer administrar. Essa mudança se relaciona às novas condições históricas, nas quais o Estado nem é mais o grande planejador e nem é mais o grande empreendedor, como o foi no passado, quando ele era o senhor na ação pública. Hoje em dia, os planos são adjetivados de estratégicos e têm a característica de articular a ação pública com a privada. Nessa articulação, a ação privada tem disparadamente maior liberdade de propor ações e estratégias que anteriormente, quando o planejamento era fortemente centralizado pelo Estado.

Interessante é que em grande parte os planos estratégicos são de responsabilidade de empresas de consultoria internacional. Um exemplo é bastante elucidativo e vale mais que mil palavras. O Consórcio Brasiliana formado pela Booz Allen \& Hamilton, Bechtel International e ABN Amro Bank, foi escolhido por meio de licitação pública para elaborar o Estudo dos Eixos Nacionais de Integração e Desenvolvimento.

Assim, em vez de planejamento, da discussão sobre planejamento, temos a predominância da palavra gestão nas linhas de pesquisa. O que significa, análise da gestão. Dos planos? Não, mas dos planos estratégicos, sim. Um outro olhar revela a ênfase dada aos programas ao termo ordenamento que revela a preocupação em se compreender as estratégias e as ações públicas e privadas sobre o território, sendo o território o objeto de gestão. O planejar cede, assim, lugar ao ordenar. Está claro que o Estado, agora, mais dirige estratégias e ações do que as planeja. É dessa conjuntura e da sobressaliência no uso das palavras gestão e ordenamento, que deriva o emprego frequente dos termos: território, territorialidade, uma vez que o que se ordena é o território, devido à dimensão política e estratégica que ele contém. Torna-se claro, assim, porque as linhas de pesquisa se referem ao ordenamento urbano e regional, ordenamento ambiental e, vale destacar, à própria palavra geopolítica. E, muito menos ao termo planejamento.

Outro ponto a destacar. As linhas de pesquisa dos programas se voltam para a análise regional, em especial no programas do nordeste e sul. A ênfase na relação entre região e condições naturais aparece nos programas do nordeste e centro-oeste. No Ceará, por exemplo, as linhas de pesquisa se referem à questão do litoral e zona costeira; em Goiás, a vinculação é com o cerrado e, na região Norte, com a Amazônia. No programas do sudeste, que são 16, as linhas de pesquisa pouco se referem à ideia de região, salvo o programa da UFF, da Universidade Federal Fluminense, e o da UNESP (Universidade Estadual Paulista Júlio de Mesquita Filho), campus de Presidente Prudente.

O que isso revela? Isso evidencia claramente que houve uma naturalização da dimensão da pesquisa regional e um quase esquecimento dela na região mais industrializada e urbanizada do pais. Não que essa referência à natureza não seja válida, muito pelo contrário. No entanto, a ênfase na relação entre as condições naturais e o recorte regional conduz ao empobrecimento da apreensão de outras dimensões analíticas que poderiam ser enriquecedoras do conhecimento por meio de outros recortes, de outras delimitações regionais. Mostra também, uma migração de conteúdos próprios e tradicionais da análise regional para a o campo renovado da geopolítica. Ou seja, a dimensão política da análise regional e dos estudos da política regional e do regionalismo acabaram se transformando em geopolítica, incorporando a discussão sobre ordenamento territorial, aparecendo, agora, como uma temática inovadora.

Essas mudanças guardam estreita relação com o fato de que os estudos regionais nos moldes clássicos - como realização da síntese geográfica - mostraram sinais de esgotamento; quando muito servem mais para diagnósticos do que para produção de conhecimento novo. 
Uma outra observação digna de nota remete aos tradicionais campos da geografia: à geografia agrária e à geografia urbana. Os produtos agrícolas e mesmo a pecuária indicaram por muito tempo temas de pesquisa em que a ênfase da abordagem se situava na questão do uso da terra, nas áreas produtoras de determinado produto - café, algodão, milho, por exemplo - ou de criação. Essa forma de produzir o conhecimento se alterou com a intensificação da capitalização do campo no Brasil e com a influência da vertente marxista na geografia que trouxe a ênfase na questão da propriedade da terra e das relações sociais de produção. Mas, essa ênfase está se arrefecendo.

Pesquisas voltadas para as cadeias produtivas, os circuitos de produção e para o agronegócio se desenvolveram bastante, nos anos mais recentes. São bastante significativas em vários programas de pós-graduação em geografia. Como observamos, a ênfase na questão da propriedade da terra e nas relações sociais de produção está diminuindo, tanto quanto as pesquisas relativas aos movimentos sociais no campo, que até recentemente eram bastante privilegiadas.

Já em relação ao urbano, as linhas de pesquisa destacam o metropolitano e o processo de alterações que vem ocorrendo nas cidades em geral. $\mathrm{O}$ destaque dado à temática urbana atesta $\mathrm{o}$ reconhecimento de que a sociedade atual é cada vez mais urbana e que as metrópoles assumem grande relevância nos dias atuais porque são elas o lócus privilegiado da gestão do capital, num contexto em que a produção industrial é mais dispersa territorialmente. A cidade coloca-se, então, como tema importante de investigação destacando-se a questão da fragmentação e segregação do espaço urbano.

Uma outra observação, a sexta a registrar, é que emergem com força as seguintes linhas de pesquisa: o ensino da geografia e a cultura. Quanto ao ensino da geografia, embora esse tema figure nas linhas de pesquisa dos programas, ainda aparece de forma tímida. Se há consenso absoluto sobre algo, esse é o de que não há projeto de desenvolvimento de um país sem se colocar em pauta a educação. É bom lembrar que desenvolvimento não se confunde com crescimento econômico, uma distinção que, infelizmente conhecemos de perto. Somos um país rico, uma das dez primeiras economias do mundo, com estratos vultosos da população em situação de pobreza e com pouco acesso à educação e à cultura. A massificação dessas não se fez acompanhar por qualidade, o que faz questionar se se trata mesmo de educação e de cultura. O tema do ensino é importante devido à responsabilidade social da Universidade pela formação de quadros capacitados para o ensino. Para o ensino da geografia e, no caso em pauta, para a formação de docentes para o ensino superior e de pesquisadores de alto nível.

O outro tema, o da cultura, se destaca e se afirma como um tema que ressurge da sua fase de ostracismo, das primeiras décadas da segunda metade do século XX. Ele aparece com uma nova dimensão, num contexto em que a cultura passou a ser uma nova esferas importante de inversões de capital. Constitui, hoje, seara importante da economia. Isso não quer dizer, contudo, que as pesquisas desenvolvidas sobre cultura se voltem para os aspectos econômicos dessa temática, o que poderia enriquecê-las. Em geral, é mais comum o tratamento culturalista.

Analisando-se as linhas de pesquisa registradas pelos Programas, relativas ao ano de 2012, podemos ver a frequência com que cada termo aparece, observando-se o eixo horizontal. Esse gráfico foi elaborado pelo Prof. Dr. João Lima Sant'anna Neto, coordenador da área de Geografia na CAPES, no triênio 2010-2013.

Podemos ver que no item categoria/conceito é notório o destaque, como indicamos da categoria/conceito Ambiente e da categoria/conceito Território, bem como é significativo o encolhimento da palavra Natureza. 
Figura 1 - Linhas de Pesquisa, (2012)

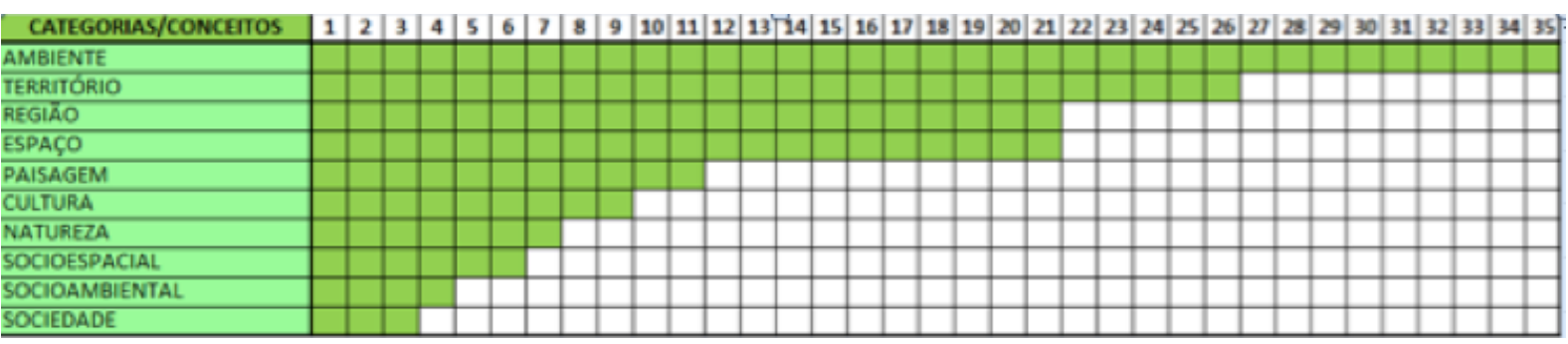

Elaboração: Sant'Anna Neto, 2013.

Em síntese, algumas linhas de pesquisa emergem com força; outras tradicionais ou que figuraram na segunda metade do século XX até os anos 90, foram esquecidas. Cabe a nós compreendermos o sentido de tais mudanças. Cabe a nós termos consciência sobre o rumo das mudanças, sobre nossas escolhas, sobre as escolhas que temos feito. Só assim poderemos não nos surpreender com os resultados em curso e intervir de forma responsável construindo o que de fato queremos.

\section{CONSIDERAÇÕES FINAIS}

Um olhar sobre as grandes linhas de pesquisa dos programas revela grandes mudanças nas temáticas de pesquisa dos programas de pós-graduação em geografia que vem sendo desenvolvidas atualmente. Revela que só se compreende tais mudanças contextualizando-as, mesmo que de forma generalizada. Se são os homens que produzem sua história segundo as condições históricas dadas, as linhas de pesquisa desenvolvidas pelos programas de geografia também são concebidas segundo condições históricas dadas, pois guardam relação com o contexto em que se dão, incluindo-se aí o de ordem epistemológica, aqui não considerados.

Natureza? Cartografia? Recursos Naturais? Planejamento? Não. Agora é a vez do ambiente, da análise ambiental, dos espaços de sustentabilidade, dos sistemas de informação geográfica, dos modelos de análise espacial, da gestão, do ordenamento territorial, da cultura... Longe de se pensar que são meros modismos, essas mudanças emanam de uma lógica e de um momento da história, nesse sentido são uma resposta tanto conjuntural como epistemológica. Torna-se compreensível, o que intrigou a muitos, quando se soube que na área de geografia da CAPES havia um programa de pós-graduação intitulado de Tratamento da Informação Espacial — da PUC/Minas, reconhecido pela CAPES em 1977. Diferentemente dos demais programas, não era denominado de Geografia. Valia, cremos, chamar a atenção para o título e para o público alvo não restrito aos geógrafos, mas interessando, também, a arquitetos, geólogos, economistas e profissionais de áreas afins. Só recentemente é que o nome Geografia foi incorporado ao título.

Muito embora a análise tenha se referido às grandes linhas de pesquisa registradas na Proposta do Programa (Caderno de Indicadores) relativa a cada programa da CAPES, o quadro abaixo informa, também, o nome da área de concentração do programa. As sub linhas, como dissemos, não apresentam informações consistentes, pois há linhas de pesquisa que agrupam vários projetos ao lado de linhas relativas a um só projeto e linhas registradas sem que tenha efetivamente tido um trabalho concluído ou disciplinas correlatas a elas ministradas.

Finalizando essa discussão sobre as características, mudanças, modismos e sentido das linhas de pesquisa em Geografia, gostaríamos de expressar que os aspectos aqui tratados poderiam ser ampliados. O objetivo, porém, como dissemos no início do texto foi apenas o de realizar uma apreciação geral das mudanças recentes em algumas temáticas que os programas de pós-graduação em geografia vêm desenvolvendo. 


\section{REFERÊNCIA BIBLIOGRÁFICA}

CAPES - Coordenação de Aperfeiçoamento de Pessoal de Nível Superior. Avaliação. Disponível em: $<$ http://www.capes.gov.br>. Acesso em: vários dias de 2013 e 15-02.2014.

DEVRY - DeVry Education Group. Disponível em: <www.devryeducationgroup.com>. Acesso em 08.05.2013.

FANOR/DEVRY. Disponível em: <http://www.fanor.edu.br>. Acesso em: 08.05. 2013.

SANT’ANNA NETO. Desafios e Perspectivas da Geografia Brasileira. Palestra proferida junto ao Programa de Pós-Graduação em Geografia da Universidade Federal de Santa Maria. Santa Maria, maio de 2013. 20 slides, color.

UNIVERSIDADE ANHEMBI-MORUMBI. Portal. Disponível em: $<$ http://portal.anhembi.br $>$. Acesso em: 08.05. 2013.

Trabalho enviado em maio de 2013

Trabalho aceito em junho de 2013 